Quoc Toan Phan, ${ }^{1,2,3} \&$ Anh Phong Bui ${ }^{1}$

\title{
Description of Coeliccia diehlae sp. $n$. from the Central Highlands of Vietnam with keys to the males and females of the pyriformis-group (Odonata: Zygoptera: Platycnemididae)
}

https://doi.org/10.23797/2159-6719_24_3

Published: 27 May 2021 (Received: 27 September 2020, Accepted: 5 October 2020)

Coeliccia diehlae sp. n. (holotype male from Ko Roong Commune, Ka Bang District, Gia Lai Province, Central Highlands of Vietnam, deposited in the Zoological Collection of Duy Tan University) is described based on both sexes. This species belongs to the pyriformis-group and comes closest to Coeliccia phamiha Phan \& Tran, 2018. Keys to the males and females of the pyriformis-group are provided.

http://www.zoobank.org/urn:lsid:zoobank.org:pub:09621225-FFE8-477F-ACD8-605BC100A647

Keywords: damselfly, dragonfly, new species

\section{Introduction}

Kompier et al. (2020) listed a total of 28 species of Coeliccia from Vietnam and first introduced the pyriformis-group including the following seven species: C. caerulea Kompier, Dow \& Steinhoff, 2020, C. cyanomelas Ris, 1912, C. curua Kompier, Dow \& Steinhoff, 2020, C. mientrung Kompier \& Phan, 2017, C. phamiha Phan \& Tran, 2018, C. pyriformis Laidlaw, 1932 and C. uenoi Asahina, 1997. Males of these species are characterized by a genital ligula terminal segment with an apical flap and two apico-lateral flagella. Among these, Coeliccia phamiha differs from all other members by the combination of large blue antehumeral markings covering most of the mesepisternum black S9 - 10 and whitish anal appendages in the male and entire middle pronotal lobe yellowish and posterior pronotal lobe with a rounded triangular extension in the female (Phan \& Tran 2018). Here, we describe another species of the pyriformis-group, Coeliccia diehlae sp. $n$. from the Central Highlands of Vietnam. By the similarity of the large antehumeral markings covering most of the mesepisternum and the structure of genitalia ligula with apical half of the flagellae scimitar-like, the new species most closely resembles C. phamiha in the group. Keys to the males and females of the pyriformisgroup are provided.

\section{Materials and Methods}

Methodology of collecting and preservation of the damselfly specimens in the field, photography of the habitus and illustrations follow Phan \& Tran (2018). Morphological terminology follows Kompier et al. (2020).

The following specimens of Coeliccia spp. are used to illustrate their structure in this study: Coeliccia uenoi (1 \&, Cuc Phuong National Park, Ninh Binh Province, 25 June 2018, Q.T. Phan leg.); C. pyriformis ( 1 , Tam Dao National Park, Vinh Phuc Province, 12 June 2020, Q.T. Phan

1 Center for Entomology \& Parasitology Research, College of Medicine \& Pharmacy, Duy Tan University, Da Nang, 550000 , Vietnam

2 Faculty of Medicine, College of Medicine \& Pharmacy, Duy Tan University, Da Nang, 550000, Vietnam

3 Corresponding author. Email: pqtoan84@gmail.com; phanquoctoan1@dtu.edu.vn 
leg.); C. cyanomelas (1 , Pia Oac National Park, Cao Bang Province, 16 May 2015, Q.T. Phan leg.; C. mientrung (1 $q$, Sao La Nature Reserve, Thua Thien Hue Province, 18 September 2015, Q.T. Phan leg.).

Abbreviation S1-10 indicates abdominal segments 1 to 10.
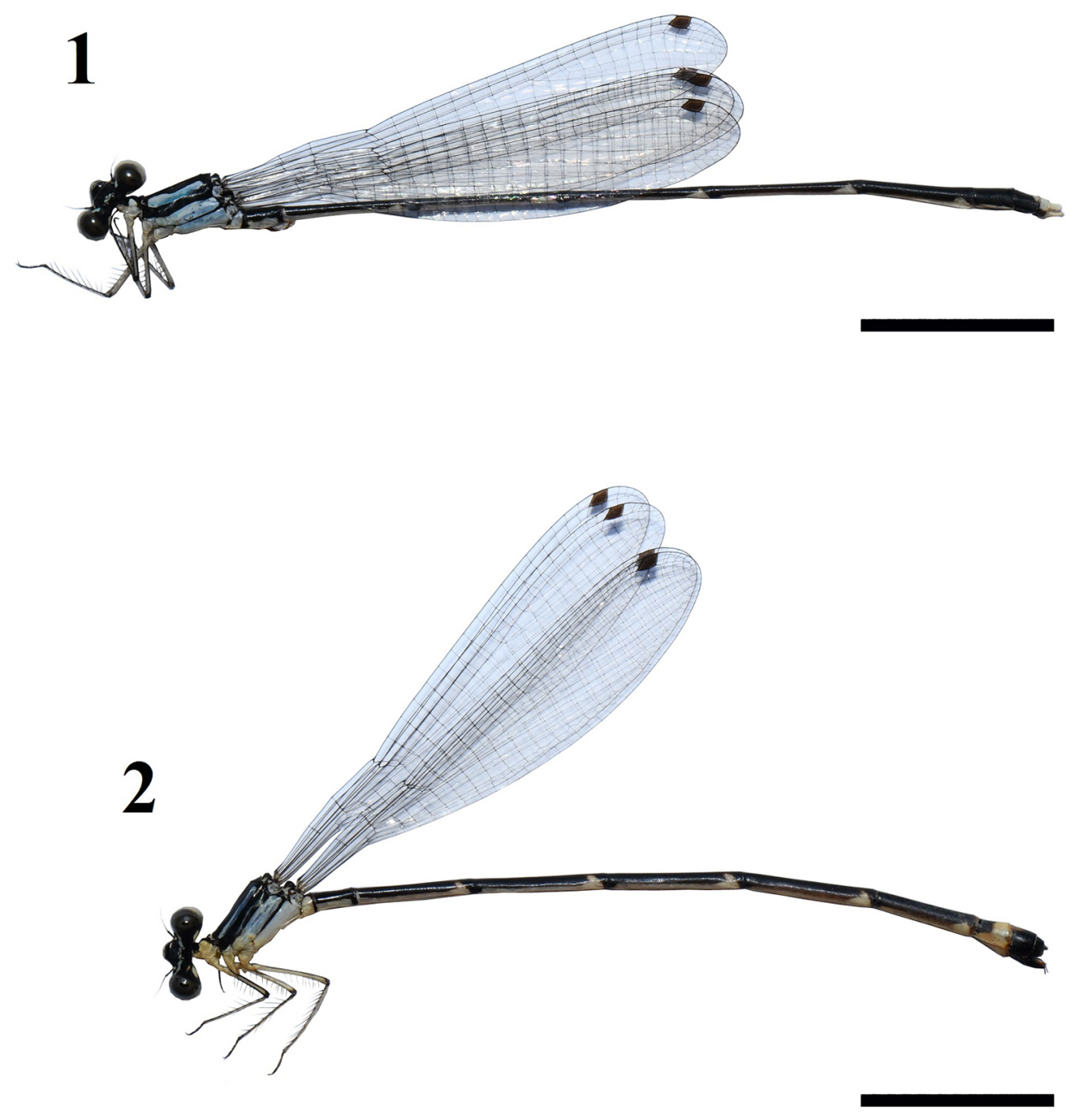

Figures 1-2. Habitus of Coeliccia diehlae sp. n. (1) holotype male \& (2) paratype female. Scale bar $=$ $1 \mathrm{~cm}$. 


\section{Results}
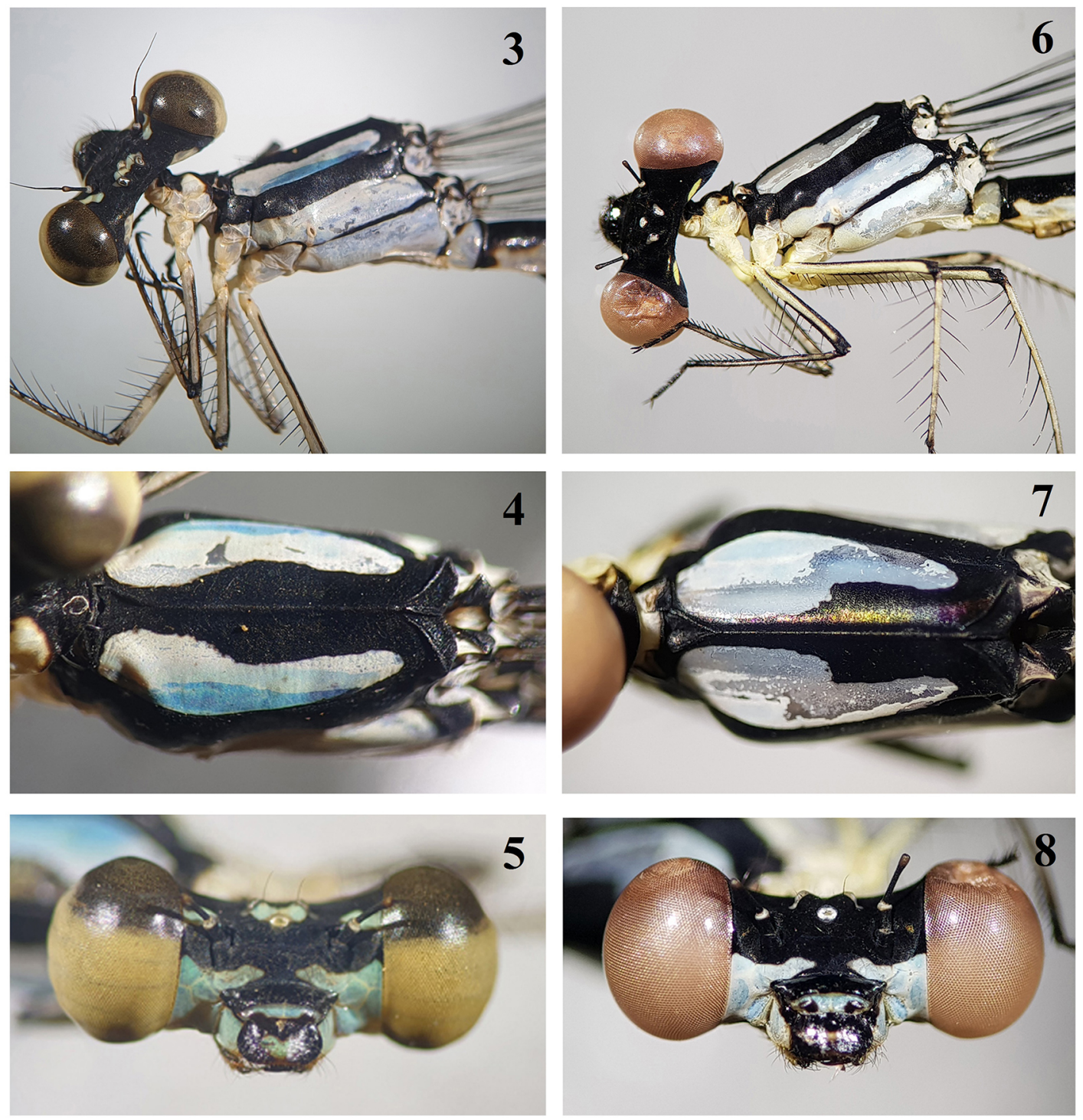

Figures 3 -8. Male characters comparison of [3 - 5] Coeliccia diehlae sp. n. \& [6 - 8] C. phamiha (holotype male, rearranged from Phan \& Tran 2018). (3, 6) head and thorax, lateral view; (4, 7) synthorax, dorsal view; $(5,8)$ head, frontal view.

\section{Coeliccia diehlae sp. n.}

\section{Etymology}

Diehlae, a noun in the genitive case, after Ms. Anna Diehl (born 31 August 1942) of Kaiserslautern, Germany, in appreciation of her support of the first author's odonatological research through the International Dragonfly Fund. 


\section{Type specimens}

Holotype $\delta^{\top}$ : Mature male, Ka Pang Stream (14.3064 N, $108.4488^{\circ}$ E; altitude $\left.633 \mathrm{~m}\right)$, Ko Roong Commune, Ka Bang District, Gia Lai Province, 28 June 2019, Q.T. Phan \& Q.P. Ngo leg.; - Paratypes: $8 \hat{\delta}, 4$ , all mature, same data as holotype; 2 , both mature, an open rocky stream near a hydroelectric dam $\left(14.684^{\circ} \mathrm{N}, 108.766^{\circ} \mathrm{E}\right.$, alt. $\left.923 \mathrm{~m}\right)$, Dak Roong Commune, Ka Bang District, Gia Lai Province, 24 May 2018, Q.T. Phan leg.

\section{Type specimen deposition}

All type specimens of the new species are deposited in the Zoological Collection of Duy Tan University, Danang, Vietnam. One male and one female from the type locality will be placed in the private collection of Dr. Rosser W. Garrison, Sacramento, USA.

\section{Diagnosis}

The characters of male genital ligula of the new species with an apical flap in the terminal segment and two apico-lateral flagella (Figures $11-12$ ) help to place it in the pyriformis-group. Within this group, the male of $C$. diehlae differs from all other species by the combination of synthorax with a large blue arcuate antehumeral stripe (Figure 3) and dorsal S9-10 including anal appendages offwhite or cream (Figures 9-10). In the female, the combination of a slender triangularly shaped posterior pronotal lobe of prothorax (Figure 21), the blue pattern on head and thorax (Figure 19) and black S9 (Figure 23) help to distinguish it from all other species in the pyriformis-group (apart from the still unknown female of C. curua) and all other known females of Coeliccia species in Vietnam.

\section{Description of holotype male}

Head (Figures 3, 5). Labrum black with blue marking centrally. Anteclypeus blue with two black spots on lower margin; postclypeus entirely black; genae and base of mandibles blue, the colour extending to just below the first segment of antennae and inward over postclypeus, although not completely meeting in the middle; antennae black accept top of first segment white and of second segment dark yellowish; head matte black dorsally apart from two short bluish stripes behind antennae from the margin of compound eye, a bluish stripe located between anterior and posterior ocelli, two tiny bluish spots adjacent to posterior ocelli and two rectangular-shaped bluish postocular spots; compound eyes bicoloured in life, black above and bluish below (Figure 29).

Thorax (Figures 3, 4). Prothorax: Anterior and posterior pronotal lobes entirely black; middle pronotal lobe black dorsally with oval whitish marking laterally; propleuron whitish. Synthorax: mesepisternum black with a large blue shield-like antehumeral marking covering most of mesepisternum, broad anteriorly, slightly curved and gradually narrowing and becoming parallel sided; mesepimeron mostly black; metepisternum and metepimeron blue except for a narrow metapleural stripe and a black line along anterior margin of metinfraepisternum; metinfraepisternum pale blue.

Legs (Figure 3). Coxae and trochanters grayish white; femora and tibiae whitish with black lines on inner and outer surfaces; armature claws brownish black.

Wings. Hyaline, 16-17 postnodal cross veins in both wings; pterostigma brown, surmounting 1.5 cells.

Abdomen (Figures 1, 9, 10). S1 largely whitish blue, black dorsally; dorsal half S2 black, white ventrally; S3 - 7 black dorsally and white ventrally, with subapical whitish annulus; S8 black dorsally, narrowly white ventrally; posterior margin of dorsal S9 with two distinct whitish spots; dorsal half of S10 whitish, ventral half black (Figures 9, 10).

Anal appendages (Figures 9, 10) white, shape typical for the genus with cerci slightly longer than S10 but distinctly shorter than paraprocts; in dorsal view (Figure 9), cerci expanded on inner margin, then gradually narrowing toward apex; in lateral view (Figure 10), cerci with apex smoothly rounded and a ventral expansion, tipped with a black tooth; paraprocts gently expanded with tip curved inward and ending in a black tooth.

Genital ligula (Figures 11, 12). The terminal segment with a flap-like fold and with a pair of long flagellae lateroapically; the apical half of each flagellum forming a scimitar-like process.

Measurements (in mm). Hind wings 27; abdomen including appendages 45. 

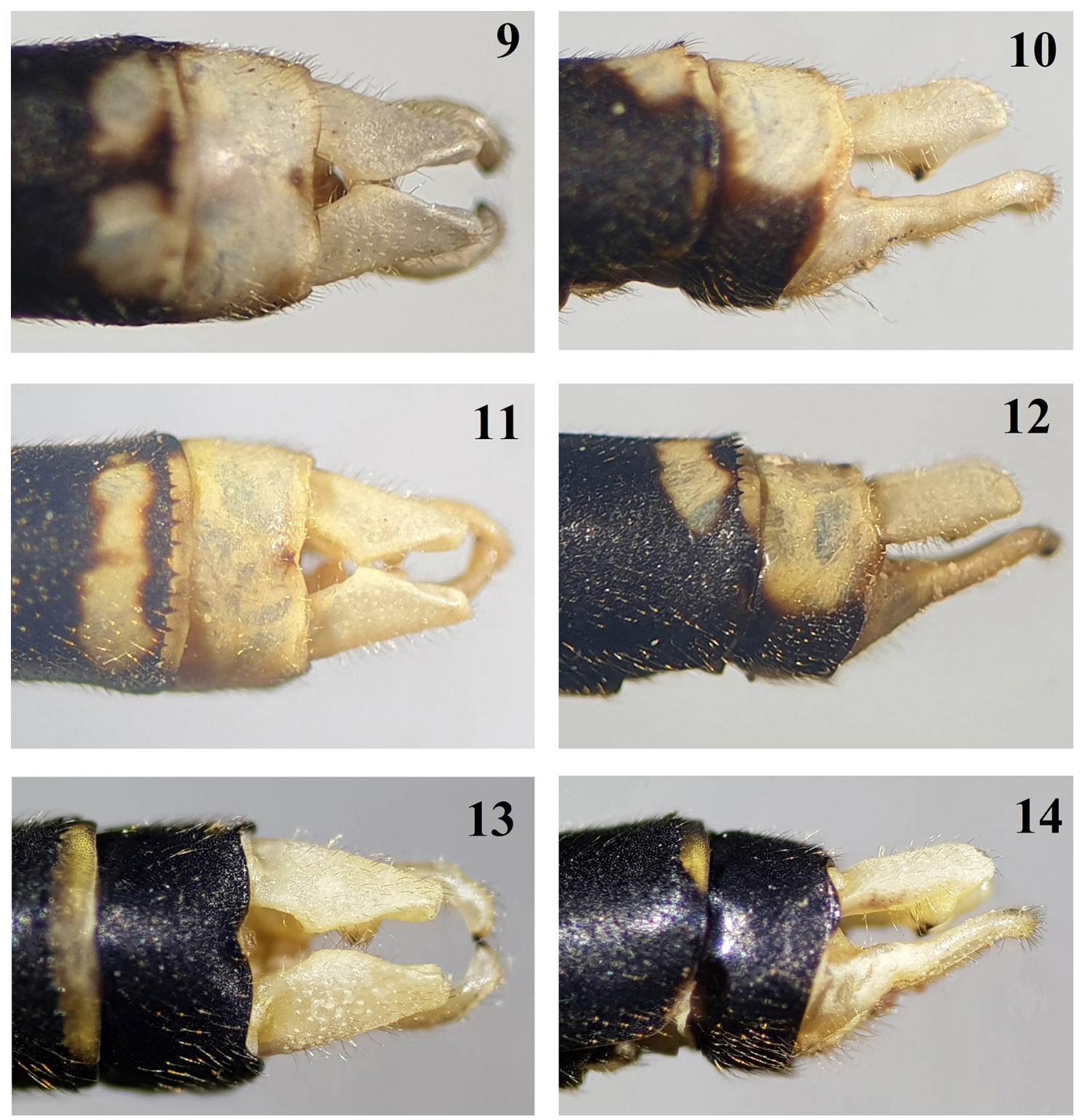

Figures 9 - 14. Appendages of Coeliccia spp. [9 - 12] Coeliccia diehlae sp. n., holotype and paratype male \& [13 - 14] C. phamiha (holotype male, rearranged from Phan \& Tran 2018). (9, 11, 13) appendages, dorsal view; $(10,12,14)$ appendages, lateral view.

\section{Variation in paratype males}

One male from the type locality differs from the holotype in having two tiny spots behind the antennae, not elongated stripes as in the holotype (Figure 3). In two male specimens from Dak Roong Commune, labrum with yellow marking and dorsal S9-10 including appendages cream (Figures 11, 12), not whitish as in holotype (Figure 9). The marking on S9 of two males from the type locality and one male from Dak Roong Commune is complete (Figure 11), not divided into whitish spots as in holotype (Figure 9). Other paratype males show little morphological variation.

\section{Description of paratype female}

Head (Figures 19, 20). Labrum black with a small yellow spot centrally. Anteclypeus black with median bluish spot; postclypeus shiny black; genae and mandibles blue, this pattern continuing above the postclypeus, remainder of frons matte black; epicranium matte black apart from a transverse 

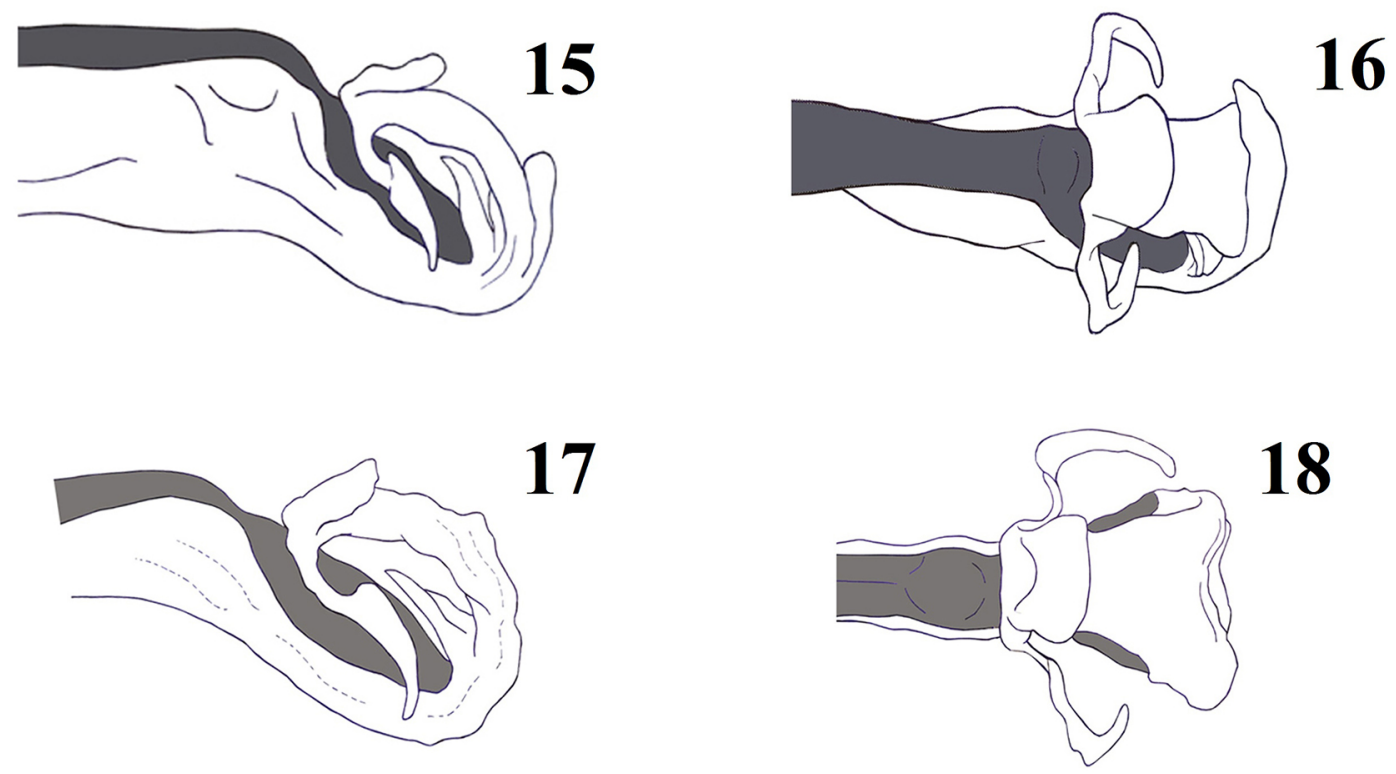

Figures $15-18$. Genital ligula of Coeliccia spp. $(15,16)$, Coeliccia diehlae sp. n. (17, 18), C. phamiha (holotype male, rearranged from Phan \& Tran 2018).

yellowish white stripe connecting from eye margin and covering ocelli and two oblong yellowish postocular spots; antennae black with top of first segment and base of second segment yellowish; compound eyes in life as in the male (Figure 31), black dorsally and bluish below.

Thorax (Figures 19, 21, 22). Prothorax: Anterior and posterior pronotal lobes black, middle pronotal lobe black dorsally, the remaining area yellowish; posterior margin of posterior pronotal lobe triangular, slender and two distinct lapels; colour pattern of synthorax as in the male but pale white instead of blue and antehumeral stripe narrow and there is no black margin to the metinfraepisternum (Figures 19, 22). Legs as in male.

Wings. Hyaline, 16-17 postnodal cross veins in fore- and hind wings; pterostigma brown, surmounting 1.5 cells.

Abdomen (Figures 2, 23). S1 largely white with posterior margin and dorsum narrowly black; S2 - 7 black dorsally and white ventrally, with subapical white annulus; S8 blackish brown on anterior half of dorsum, remainder whitish brown; S9 - 10 almost completely black (Figure 23).

Anal appendages (Figure 23). Cerci blackish, half as long as S10, ovipositor black with small yellow anterior spot and on apex of dorsum.

Measurements (in mm). Hind wing 28; abdomen including appendages 42.

\section{Variation in paratype females}

Paratype females show no significant morphological differences from the female used for the description apart from a specimen with a narrow yellowish stripe on the dorsum of S9.

\section{Habitat and ecology}

Coeliccia diehlae was found along the edges of an open, rocky mountain stream (about $5-12 \mathrm{~m}$ width) bordered by shaded vegetation. Other Coeliccia species collected there included C. hayashii Phan \& Kompier, 2016, C. rolandorum Kosterin \& Kompier, 2017 and C. scutellum Laidlaw, 1932. 

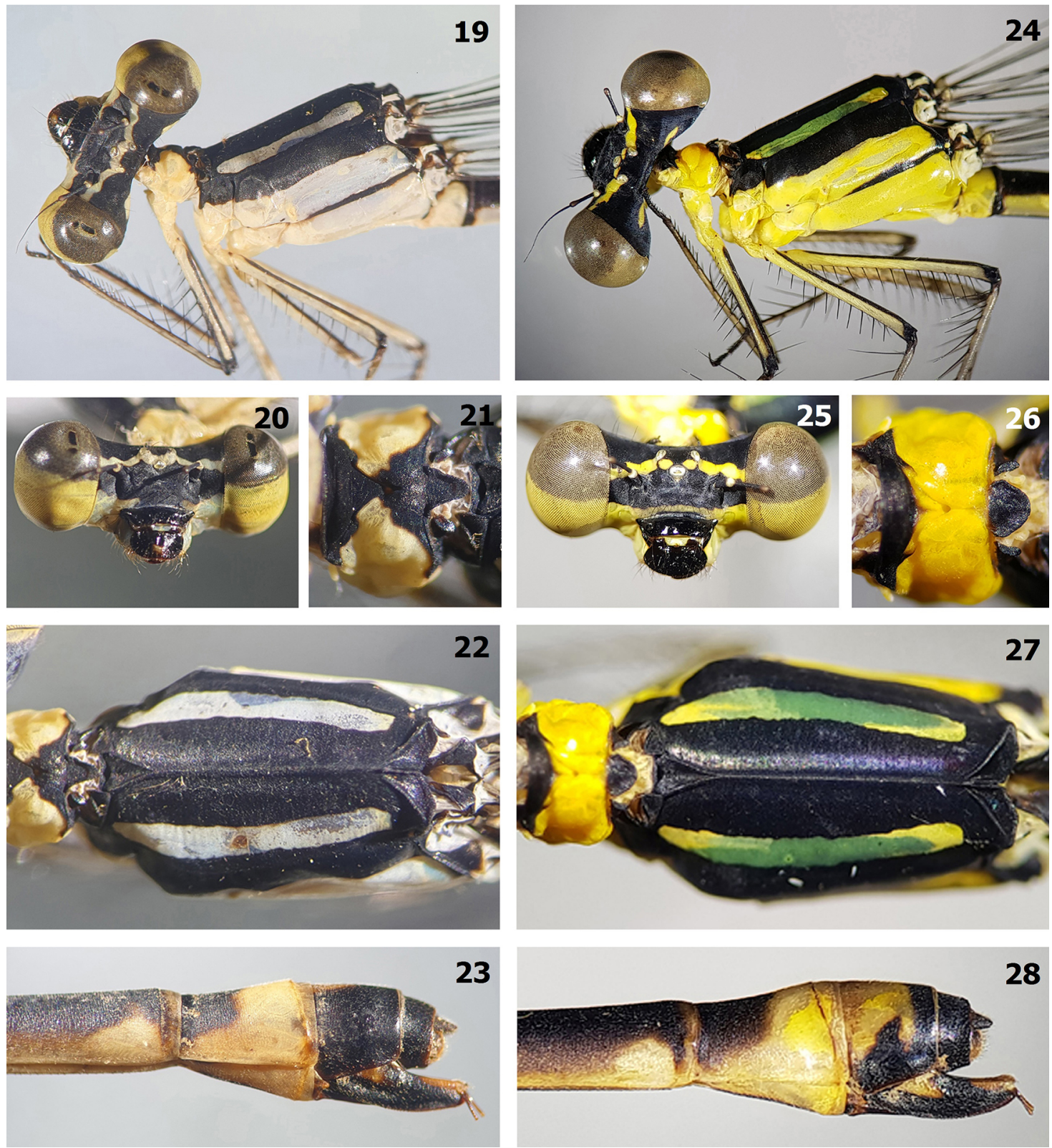

Figures 19 - 28. Female characters comparison of [19 - 23] Coeliccia diehlae sp. n. \& [24 - 28] C. phamiha (paratype female, rearranged from Phan \& Tran 2018). $(19,24)$ head and thorax, lateral view; $(20,25)$ head, frontal view; $(21,26)$ prothorax, dorsal view; $(22,27)$ synthorax, dorsal view; $(23,28)$ abdominal tip, lateral view. 

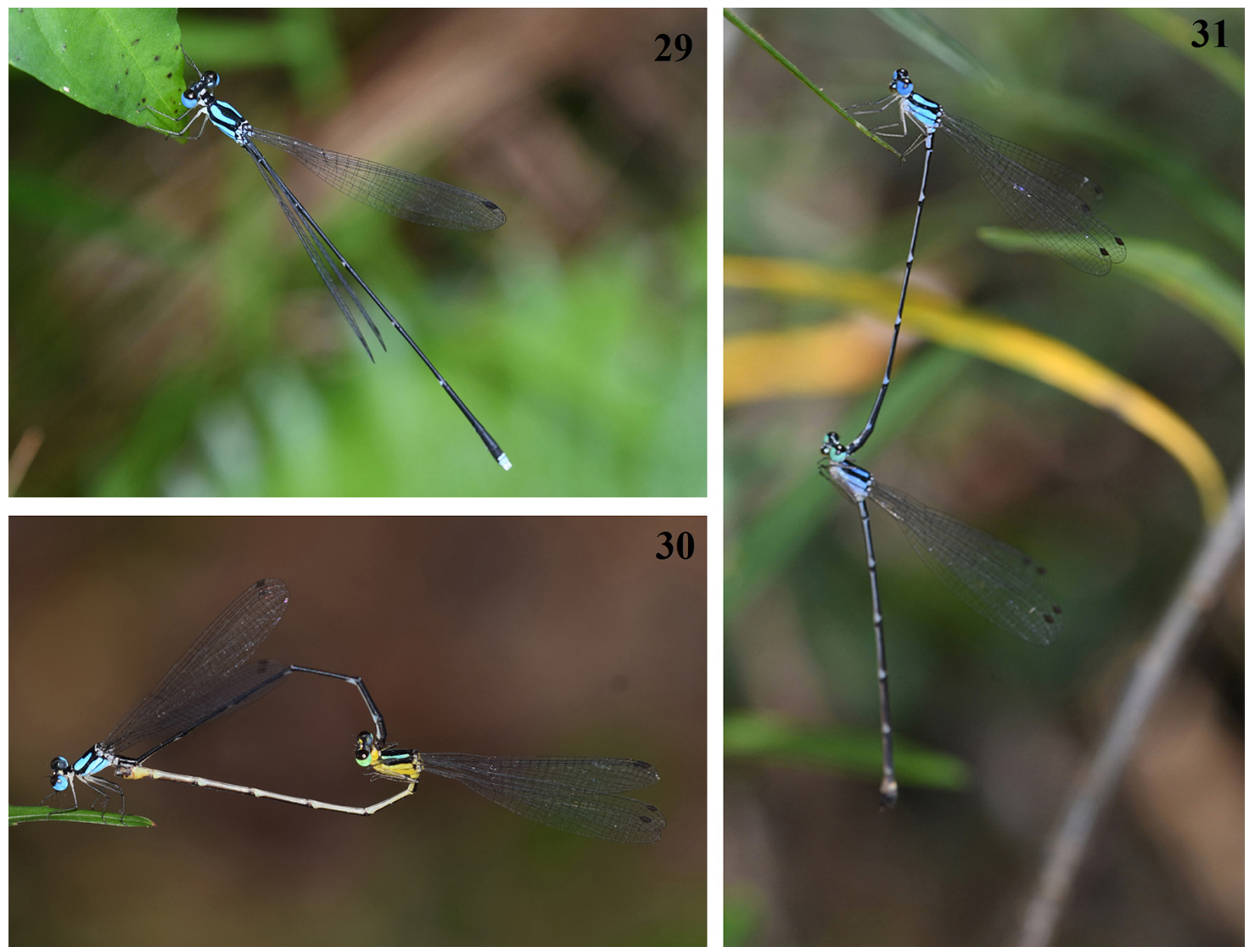

Figures 29 - 31. Habitus of Coeliccia diehlae sp. n. and C. phamiha at their type locality. (29) C. diehlae sp. n., male (photographed on 28 vi 2019); (30) C. phamiha, copula (photographed on 14 vi 2018); (31), C. diehlae sp. n., tandem (photographed on 28 vi 2019).

\section{Key to the males and females of pyriformis-group species from Vietnam}

Males: Keys to the males of pyriformis-group are based on our available specimens apart from the male of P. curua, which is adopted from Kompier et al. (2020).

1 Synthorax with large blue shield-like antehumeral markings $\ldots \ldots \ldots \ldots \ldots 2$

- Synthorax with narrow antehumeral stripes $\ldots \ldots \ldots \ldots \ldots \ldots \ldots \ldots$

2 The large blue shield-like antehumeral markings, covering most of the mesepisternum (Figure 4); flagella of the genital ligula are directed laterally and posteriorly,

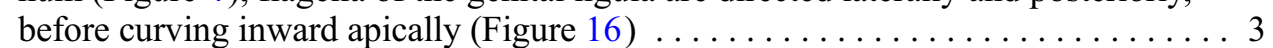

- The large blue oval antehumeral markings, covering half of the mesepisternum; flagella of the genital ligula robust and directed first laterally and then anteriorly (Kompier et al. 2020: Figs. 4d, 12, 13) ........................ 4

3 Dorsal S9-10 white or cream (Figures 9-12) $\ldots \ldots \ldots \ldots \ldots \ldots$ diehlae

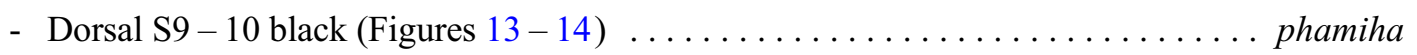


4 The flagellae of genital ligula are directed anteriorly, hidden in ventral view under terminal segment, but apical third directed laterally and visible in ventral

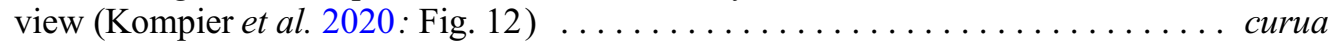

- The flagellae of genital ligula are robust and directed first laterally and then anteri-

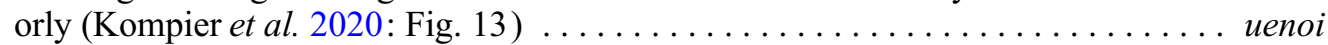

5 The antehumeral stripes are very short, often paired with another smaller spot; S8 10 including appendages dark blue or black (Yu et al. 2019: Figs. 4-5) . . . . cyanomelas

- The antehumeral stripes long; abdominal tip including appendages yellow or white 6

6 S9 entirely black, S10 white with black marking dorsally; appendages white (Kom-

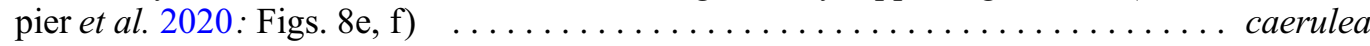

- Dorsal S9-10 including appendages yellowish $\ldots \ldots \ldots \ldots \ldots \ldots \ldots$

7 The yellow on S9 is restricted; the flagella at the apex of the terminal segment of the genital ligula run more parallel to the terminal segment, and their apices are not hammerhead shaped (Kompier \& Phan 2017: Figs. 1 - 2) . . . . . . . . . . mientrung

- The yellow covering dorsal S9; the flagella of the genital ligula run perpendicular to the terminal segment and their apices are hammerhead shaped

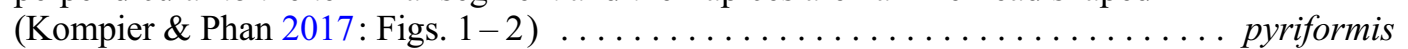

\section{Females: Keys to the females of pyriformis-group (except C. curua, which is unknown).}

1 Posterior pronotal lobe structurally complex with the central protrusion curving backward, forming two laterally pointed extensions (Figure 32$) \ldots \ldots \ldots \ldots \ldots$. . . . . .

- Posterior pronotal lobe structurally simple without lateral extensions . . . . . . . 2

2 Posterior pronotal lobe squarish (Figure 33$) \ldots \ldots \ldots \ldots \ldots \ldots \ldots \ldots \ldots$ pyiformis

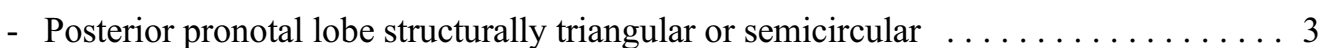

3 Middle pronotal lobe is completely yellow; posterior pronotal lobe semicircular

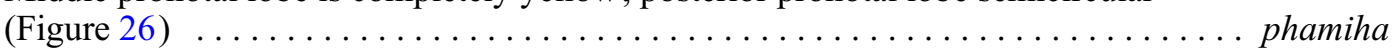

- Middle pronotal lobe black with yellow markings $\ldots \ldots \ldots \ldots \ldots \ldots \ldots \ldots \ldots$

4 Posterior pronotal lobe very small, triangular (Figure 34); S8 - 9 black with yellow-

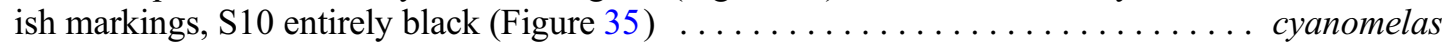

- Posterior pronotal lobe large, triangular (Figure 36); S8 - 9 largely yellowish, S10

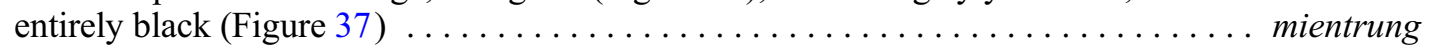

- Posterior pronotal lobe large, slightly semicircular (Figure 38); S8 largely pale blue, S9 -10 entirely black (Figure 39$) \ldots \ldots \ldots \ldots \ldots \ldots \ldots \ldots \ldots \ldots \ldots \ldots \ldots$

- Posterior pronotal oblong triangular (Figure 21); S8 largely yellowish, S9 - 10 black

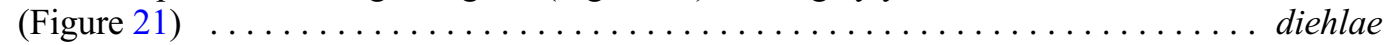



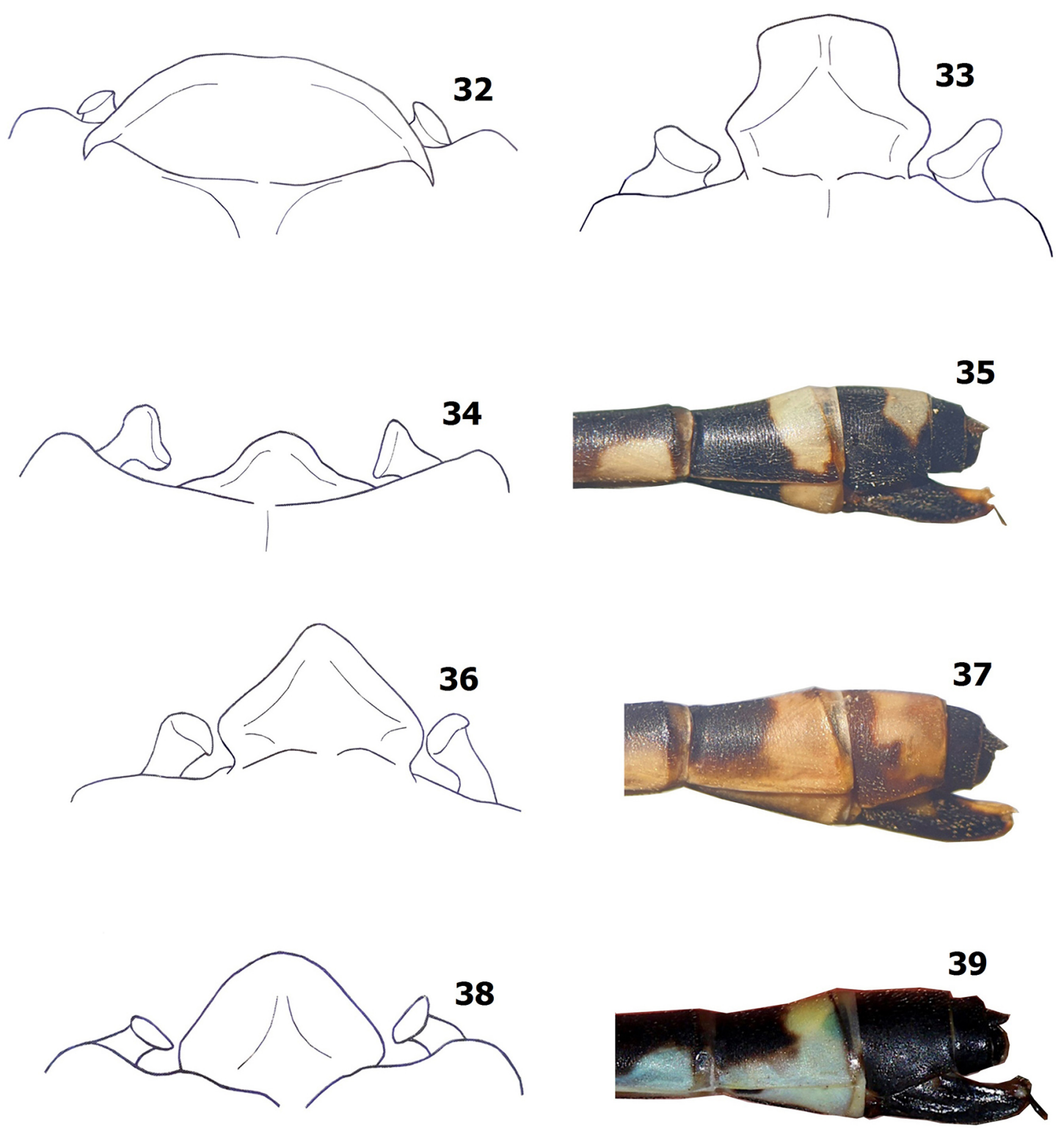

Figures 32 - 39. Posterior pronotal lobe and abdominal tip of Coeliccia spp., female. (32), C. uenoi, Cuc Phuong National Park; (33), C. pyriformis, Tam Dao National Park; (34-35), C. cyanomelas, Pia Oac National Park; (36-37), C. mientrung, Sao La Nature Reserve; (38-39), C. caerulea (adopted from Kompier et al. 2020).

\section{Discussion}

Although keys to the males and females of pyriformis-group are provided here, it remains difficult to separate similar species within the pyriformis-group. Therefore, we provide the detailed differential diagnosis on the grounds of consistent sets of characters for males and females as following. Within the pyriformis-group, the males of Coeliccia diehlae, C. phamiha, C. curua and C. uenoi all have large blue shield-like or broad antehumeral markings covering most or at least a large part of the 
dorsum. In $C$. diehlae and C. phamiha, the antehumerals cover most of the mesepisternum (Figures 4,7 ), whereas they are relative shorter and cover only slightly more than half the length of mesepisternum in C. curua and C. uenoi (Figs. 5a, d in Kompier et al. 2020).

The detailed comparison of the different characters between the male of Coeliccia diehlae and $C$. phamiha are: Epicranium of $C$. diehlae with two stripes adjacent to antennae and another stripe between three ocelli (Figure 3) while those stripes are absent in C. phamiha (Figure 6); in C. diehlae, the antehumeral marking is much narrower medially than in C. phamiha (Figures 4, 7); dorsal S910 of diehlae is whitish or yellowish (Figures 9,11) but black in C. phamiha (Figure 13); apical half of flagella of $C$. diehlae relatively shorter, curved at the level of flap-like fold structure (Figure 16), not extending further posteriorly as in C. phamiha (Figure 18).

Female of Coeliccia diehlae can be distinguished from most other Vietnamese Coeliccia females by the slender triangular posterior pronotal lobe of prothorax, the blue head and thorax color pattern and black S9. Most other Coeliccia species have S9 yellowish. Theslender triangular and flat posterior pronotal lobe and black S9 are somewhat similar to that of the female of Coeliccia mattii Phan \& Kompier, 2016 (see Phan \& Kompier 2016: Figs. 2B, 5B) but the colour pattern of head and thorax of $C$. diehlae is blue, not yellowish as in C. mattii. The detailed comparison with the females of the pyriformis-group is provided in the key. Coeliccia caerulea also has black S9 (Figure 39) but posterior pronotal lobe large, semicircular (Figure 38). we compare Coeliccia diehlae with its closest congener, C. phamiha: The middle pronotal lobe is largely yellowish with black marking dorsally and the posterior pronotal lobe of $C$. diehlae is oblong, triangular in shape (Figure 21) whereas the middle pronotal lobe of $C$. phamiha is completely yellowish and the posterior pronotal lobe semicircular in shape (Figure 26). Body coloration of the two species differs in both living and dead material by the following characters: The pattern on the head and thorax in C. diehlae is blue (Figures 19-22, 30,31 ), not with a blue-green antehumeral stripe and yellowish pattern as in C. phamiha (Figures $24-27$ ); the transverse stripe on epicranium of $C$. diehlae covers all three ocelli (Figure 19) but is interrupted between lateral ocelli in C. phamiha (Figure 24); middle pronotal lobe of $C$. diehlae black dorsally (Figure 21) but entirely yellowish in C. phamiha (Figure 26).

Males of the four species in the pyriformis-group with large blue shield-like antehumeral markings are allopatric and occur within different habitats in central Vietnam: Coeliccia curua and C. uenoi are limited to limestone forests in northern areas while C. diehlae and C. phamiha are thus far known only from high altitude evergreen forests in the Central Highlands of Vietnam (Figure 40).

In this study, we consider that the combination of male and female characters are sufficient to separate Coeliccia diehlae from other species in the pyriformis-group. However, it should be noted that Coeliccia species may have considerable morphological variation between distinct geographic local populations as shown for $C$. cyanomelas (Yu et al. 2019) and suggested for C. curua (Kompier et al. 2020). Kompier et al. (2020) made some reservations regarding speciation within the pyriformis-group, as it is still possible that intermediate populations will be found. Further research will benefit from the collection of long series of the different species of the pyriformis-group all across the country, which together with the DNA analysis of the whole group may further help establish specific identities and demonstrate the amount of variation within each species. 


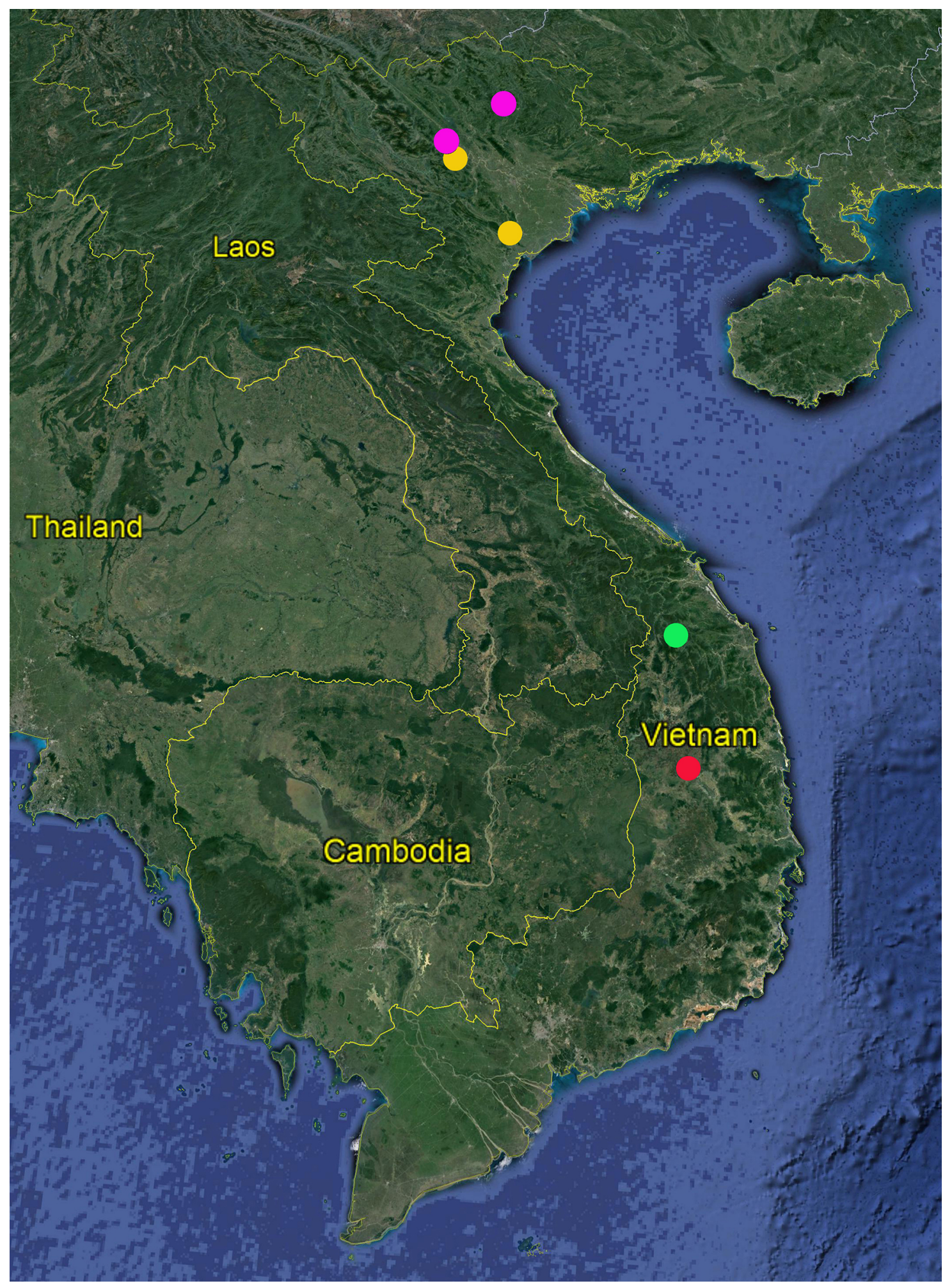

Figure 40. Distribution of males of the pyriformis-group with large shield-like antehumeral markings in

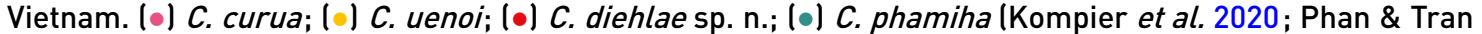
2018; this study). 


\section{Acknowledgements}

We are grateful to Mr Tom Kompier, Dr Rosser William Garrison and anonymous reviewer for revising and improving the manuscript; the International Dragonfly Fund and Dr Le Nguyen Bao, provost of Duy Tan University for supporting the first author with fieldwork; Mr Ngo Quoc Phu (Duy Tan University) for his assistance during field work and the directorate of Kon Ka Kinh National Park for providing support and permission.

\section{Funding}

This research was mainly funded by the Vietnam National Foundation for Science and Technology Development (NAFOSTED) under grant number 106.05 - 2018351.

\section{References}

Asahina, S. (1997). Records of the Northern Vietnamese Odonata taken by the expedition members from the National Science Museum, Tokyo. 5. Coenagrionidae, Protoneuridae, Platycnemididae. Bulletin of the National Science Museum, Series A Zoology, 23 (1), 17-34.

Kompier, T., Dow, R.A. \& Steinhoff, P.O.M. (2020). Five new species of Coeliccia Kirby, 1890 from Vietnam (Odonata: Platycnemididae), and information on several other species of the genus. Zootaxa, 4766 (4), 501-538. https://doi.org/10.11 646/zootaxa.4766.4.1

Kompier, T. \& Phan, Q.T. (2017). Coeliccia mientrung spec. nov. from Central Vietnam (Odonata: Platycnemididae). Zootaxa, 4247 (2), 131-140. https://doi.org/10.11646/zootaxa.4247.2.4

Phan, Q.T. \& Kompier, T. (2016). Description of two new species of Coeliccia from Vietnam (Odonata: Platycnemididae). Zootaxa, 4196 (3), 407-414. http://dx.doi.org/10.11 646/zootaxa.4196.3.4

Phan, Q.T. \& Tran, T.T.T. (2018). Description of Coeliccia phamiha sp. n. from central Vietnam (Odonata: Platycnemididae). International Journal of Odonatology, 21 (1), 45 - 53. https://doi.org/10.1080/13887 890.2017.1419885

Yu, X., Zhang, M. \& Ning, X. (2019). A study of Coeliccia cyanomelas Ris, 1912 (Odonata: Platycnemididae). International Journal of Odonatology, 22 (3 - 4), 155 - 165. https://doi.org/10.1080/13887 890.2019.1641 853 